\title{
Atlas of Defects within a Global Building Inspection System
}

\author{
Clara Pereira $\mathbb{D}^{\mathbb{D}}$, Jorge de Brito * ${ }^{\mathbb{D}}$, José D. Silvestre $\mathbb{D}$ and Inês Flores-Colen $\mathbb{D}$
}

CERIS, Instituto Superior Técnico, Universidade de Lisboa, Av. Rovisco Pais, 1, 1049-001 Lisboa, Portugal; clareira@sapo.pt (C.P.); jose.silvestre@tecnico.ulisboa.pt (J.D.S.); ines.flores.colen@tecnico.ulisboa.pt (I.F.-C.)

* Correspondence: jb@civil.ist.utl.pt; Tel.: +351-21-841-8118

Received: 30 July 2020; Accepted: 21 August 2020; Published: 25 August 2020

\begin{abstract}
Building inspection systems are essential to optimise building maintenance. In the context of developing a global building inspection system, the lack of an expeditious tool to identify defects and their urgency of repair was detected. This study intends to propose an atlas of defects applicable to several types of building elements/materials, simplifying issues associated with the diagnosis of building pathology. A database was devised using previously developed components of the global inspection system: the classification list of defects and the urgency of repair parameters. Such a database was structured using several pages, each one with tables organised according to types of defects, building elements/materials and levels of urgency of repair (five-level scale-0-4). The atlas of defects has 38 pages in total, each for a different type of defect. The levels of urgency of repair are illustrated with photographs and described with concise classification criteria. Not all levels of urgency of repair apply to all defect-building element/material combinations; levels 1, 2 and 3 are those most often considered. The proposed atlas of defects is an innovative approach, useful to assist surveyors during technical inspections of buildings, whose concept may be adapted to other inspection systems.
\end{abstract}

Keywords: building defects; building diagnosis; building envelope; building inspection system; urgency of repair

\section{Introduction}

\subsection{Background, Problem and Purpose}

The built environment has a central position in the pathway to achieve a sustainable development [1]. Several issues may be key in this context, such as urban and spatial planning, energy use, greening, material selection, design strategies, thermal comfort and indoor air quality. Additionally, building maintenance has a relevant role. Maintenance strategies, if well planned, prolong the service life of buildings, hence contributing to their constant reuse, reducing the need for new buildings and decreasing construction and demolition waste. A global reduction of consumption of resources is thus possible through effective building maintenance.

Building maintenance plans should include a combination of proactive (preventive or predictive) and reactive strategies [2]. Nevertheless, proactive strategies are preferred, as reactive maintenance tends to result from more severe damage to buildings, thus involving higher costs. Although predictive proactive strategies are those that depend the most on building inspection, to assess the real state of building elements, all strategies benefit from building inspections in some way [3,4]. In this context, inspection results are paramount, as they are used to determine the type and boundaries of repair actions, thus influencing the efficiency of those actions and global costs. To make inspection procedures as unbiased as possible, they have to be systematised in order to increase objectivity and improve 
the diagnosis results. That is the role of building inspection systems. If such systems are adopted, procedures are standardised, the collection of information is organised, the technical language is homogenised, communication is improved, inspection activities become more agile and the whole process becomes less dependent on the surveyors' knowledge and experience [5]. First and foremost, the inspection results will be more reliable.

The architecture of building inspection systems should include methods to quantify the severity of degradation and the urgency of repair of building elements, as they are associated with maintenance optimisation [6-8]. The quantification of the degree of deterioration of building elements allows prioritising interventions [9] to comply with functional requirements at a minimal cost [10].

While systematising the knowledge on building pathology, a research team from Instituto Superior Técnico (IST), University of Lisbon (UL), developed a set of expert inspection systems, each one referring to a specific type of building element/material. These systems include classification lists of defects, their causes, diagnosis methods and repair techniques, as well as correlation matrices between defects and the other items. However, building inspections are not usually focused on a single type of building element/material, considering the building as a whole instead. So, surveyors would have to use different inspection systems to assess the real condition of different types of building elements/materials. To pragmatically tackle this issue, a global building inspection system is under development at IST-UL based on the individual inspection systems (Table 1). The harmonised classification lists of the global system, referring to defects, their causes, diagnosis methods and repair techniques, have already been published [11-14]. Additionally, each type of defect, in each type of building element/material, is given specific parameters to determine its urgency of repair [11]. Within this context, the main research question emerged: how can an expeditious tool to identify defects and their urgency of repair be achieved?

This study intends to propose an atlas of defects applicable to several types of non-structural building elements/materials, trying to clarify complex issues associated with the analysis of building pathology. The elements of the global building inspection system already developed are the basis of this research - the harmonised classification list of defects and the criteria to determine the urgency of repair [11]. The proposed atlas is expected to assist building surveyors during technical inspections, whether occasional or periodic.

A brief review of quick tools to assess building pathology is carried out. Then, the materials and methods to develop the atlas of defects are described. Next, the results are presented, showing excerpts of the atlas of defects, which are then discussed in Section 4.

\subsection{Expeditious Tools to Assess Building Pathology}

Investigating building pathology is a complex process involving the observation of anomalous occurrences, deciding whether they are defects and determining their causes and origin. It may comprise elaborate discovery procedures, involving several in situ non-destructive and destructive diagnosis methods or even laboratory tests on collected samples.

Focusing on the observation of building elements to detect defects, the inspection may be aided by some simple tools. Some of these, like binoculars or the zoom of a camera, help to get a closer look at building elements and decide whether a phenomenon is worth recording or just a temporary observation hindrance (e.g., an obstacle or the reflection from another building). Other tools provide basic data on building elements and detected defects, like a tape measure, which adds dimensional information to observations, or a spirit level, which immediately confirms the orthogonality of edges and surfaces. Additionally, portable and light comparison tools developed explicitly for inspection procedures are swift diagnosis methods that can be easily carried out in every inspection site and do not require advanced knowledge or a sophisticated apparatus [15]. Crack width rulers [16-18] and colour systems' samples [19-21] are two examples of such tools widely used, both using comparison as an operation principle. 
Table 1. Expert inspection systems developed at Instituto Superior Técnico (IST), University of Lisbon (UL), which were the basis of the global inspection system.

\begin{tabular}{|c|c|c|c|}
\hline References & Buildin & g Elements/Materials & $\begin{array}{l}\text { Validation } \\
\text { Sample }\end{array}$ \\
\hline$[22,23]$ & \multirow[b]{2}{*}{ roofs } & external claddings of pitched roofs (ECPR) & $\begin{array}{l}207 \text { surfaces } \\
164 \text { buildings }\end{array}$ \\
\hline [24-26] & & flat roofs $(\mathrm{FL})$ & $\begin{array}{l}105 \text { surfaces } \\
105 \text { buildings }\end{array}$ \\
\hline$[27,28]$ & façade elements & door and window frames (DWF) & $\begin{array}{l}295 \text { frames } \\
96 \text { buildings }\end{array}$ \\
\hline$[29,30]$ & \multirow{4}{*}{ façade claddings } & wall renders (WR) & $\begin{array}{l}150 \text { surfaces } \\
55 \text { buildings }\end{array}$ \\
\hline$[31,32]$ & & $\begin{array}{l}\text { external thermal insulation composite } \\
\text { systems (ETICS) }\end{array}$ & 146 façades \\
\hline$[33,34]$ & & painted façades $(\mathrm{PF})$ & $\begin{array}{l}105 \text { façades } \\
41 \text { buildings }\end{array}$ \\
\hline$[35,36]$ & & architectural concrete surfaces (ACS) & $\begin{array}{l}110 \text { surfaces } \\
53 \text { buildings }\end{array}$ \\
\hline [37-39] & \multirow{2}{*}{ façade claddings and floorings } & adhesive ceramic tiling (ACT) & $\begin{array}{l}88 \text { surfaces } \\
46 \text { buildings }\end{array}$ \\
\hline$[40,41]$ & & natural stone claddings (NSC) & $\begin{array}{l}128 \text { surfaces } \\
59 \text { buildings }\end{array}$ \\
\hline$[42,43]$ & \multirow{3}{*}{ floorings } & \multirow[b]{2}{*}{ epoxy resin industrial floor coatings (ERIFC) } & $\begin{array}{l}98 \text { floorings } \\
35 \text { buildings }\end{array}$ \\
\hline [44] & & & $\begin{array}{l}29 \text { floorings } \\
23 \text { buildings }\end{array}$ \\
\hline$[45,46]$ & & vinyl and linoleum floorings (VLF) & $\begin{array}{l}101 \text { floorings } \\
6 \text { buildings }\end{array}$ \\
\hline
\end{tabular}

Using crack width rulers, the surveyor is provided with a small transparent rectangle with a set of printed lines ordered from thinnest to thickest [16]. Each line is identified by its thickness, allowing the easy determination of the width of a crack throughout its length. In other words, graphical data are complemented with quantitative data, providing a user-friendly instrument $[17,18]$.

Colour system's samples are a set of cards manufactured in a resistant paper and printed with solid colours in order to be compared with those of building elements observed on-site. Each solid colour is identified with a code according to the predetermined colour system, such as the natural colour system [19] or the Munsell colour system [20,21]. The use of colour samples allows comparing (i) the observed colour with that of the beginning of the service life of the building element and (ii) the observed colour in different areas of a building element or building. Once more, graphical information, complemented with coded information, allows a more accurate diagnosis methodology.

Additionally, standards EN ISO 4628-4:2016 [47] and EN ISO 4628-2:2016 [48] propose comparison methods to evaluate the degradation of paint and varnish coatings, namely the assessment of the degree of cracking and blistering, respectively. These standards provide pictorial criteria, allowing surveyors to match the visual characteristics of detected defects with those of the standard, referring to the size, quantity and density of cracking and blistering. In these situations, the assessment of coatings is also enhanced by the use of graphical information.

The advantages of the mentioned easy-to-use, graphical and informative tools to aid inspection procedures raise interest in an analogous tool to help to observe defects and systematise their diagnosis. Such a tool, proposed in this study as an "atlas of defects", would be an image-based scale to ascertain the type of detected defect and assess its urgency of repair, complemented with essential written criteria difficult to express through photographs.

Several scales are widely used in various fields of science, for instance, to measure [9] wind force (Beaufort scale), the intensity of tornadoes (Fujita-Pearson scale), hurricane winds (Saffir-Simpson 
hurricane wind scale), earthquakes (modified Mercalli intensity scale), the magnitude of earthquakes (Richter scale), mineral hardness (Mohs scale of mineral hardness), the likelihood of developing pressure ulcers (Norton scale) and the state of a person's consciousness (Glasgow coma scale). Psychometric scales are used in questionnaires, like the visual analogue scale (VAS) or the Likert scale. One of the main differences between scales is the ability to use measurable data (e.g., Richter scale) or only to consider features of phenomena (Mohs scale), sometimes with considerable levels of subjectivity.

Likewise, in the context of building inspection, several scales have been proposed to measure the degradation of building elements. Each scale is associated with a specific study or inspection system. Some of the most relevant are described next, in a non-exhaustive perspective.

The study of a Markov decision model for rationalising building maintenance [49] makes use of a six-point scale to determine the state of a building component during an inspection. This ordinal scale goes from 1 to 6 , whose condition states are described as excellent (1), good (2), reasonable (3), moderate (4), bad (5) and very bad (6). Each condition is further described with some general characteristics, which are used for direct assignment of a condition state. The set of conditions is used to associate actions with the transition between condition states to estimate and optimise maintenance costs.

The "Méthode d'Évaluation de scenarios de Dégradation probables d'Investissements Correspondants" (MEDIC) was developed for the "Energy Performance, Indoor environment Quality, Retrofit" (EPIQR) system [50-52]. The MEDIC consists of using four codes ( $a, b, c$ and $d$ ) to describe the deterioration state of building elements. Code $a$ corresponds to an element in good condition and code $d$ to an element that needs replacement. This method is based on curves of probability of deterioration determined for each type of building element. The surveyor directly assigns a code to the building element, and then, using the predetermined curves, the probability of transition to another deterioration state may be better estimated [50].

Allehaux and Tessier [53] developed a methodology to evaluate the obsolescence of office buildings. This method was prepared to audit all current building services expected in office buildings. For each predetermined obsolescence criterion and object, three ratings may be attributed according to descriptive parameters. Ratings A, B and C correspond to good, medium and poor or not sufficient condition state, respectively.

The National Aeronautics and Space Administration (NASA) developed a maintenance guide for facilities [54]. The proposed maintenance model includes three sets of metrics: the system condition index (SCI), the facility condition index (FCI) and the deferred maintenance cost estimate. Condition assessment ratings support the definition of SCI and FCI. A five-tier condition rating system is used, namely excellent (5), good (4), fair (3), poor (2), and bad (1). When a system does not exist, rating 0 is attributed.

Rodrigues et al. [55] developed a visual survey methodology to assess the defects of the building envelope of social housing. Within this methodology, an evaluation scale was proposed, composed of eight degradation levels with specific parameters for each level according to the building element, taking the intensity, extent and location of damages into account. Level 10 is the most favourable degradation level, referring to an exceptional condition, not requiring any intervention, just planned maintenance actions for conservation purposes. Level 3 is the most severe degradation level, referring to an unacceptable condition, which is unsuitable for rehabilitation and requiring replacement. The survey methodology includes a step of aggregation of results for each type of building element. That aggregation considers the same scale, attributing a global degradation level according to the relative frequencies of degradation levels of each inspected building element.

Elhakeem and Hegazy [56] proposed using the severity of various deficiencies, defined by the surveyor on a scale from 0 to 100 , to compute the overall deterioration index. That index also considers a weight attributed to each type of deficiency. The deterioration index is used to generate repair scenarios to optimise maintenance decisions, taking costs into account.

Morgado et al. $[57,58]$ proposed methodologies to implement maintenance planning in pitched and flat roofs. Those methodologies encompass the establishment of intervention priorities for maintenance 
actions. In these studies, priorities are determined by the combination of four criteria: environmental aggressiveness of the surroundings, the extent of the defect, the level of deterioration of the building elements, and the severity of the defect. The last two criteria use two different scales, both for direct assignment. The degradation condition of the building elements is rated according to a four-level scale, ranging from 0 to 3 , with the following definitions: no visible degradation (0), superficial degradation (1), moderate degradation (2) and generalised degradation (3). To determine the severity of the defects, a five-levels scale is used, from grades A to E, where A refers to "negative influence on the aesthetical aspect" and E to "risk to the safety of users". The combination of the different criteria is computed using weights and multiplying factors to determine a quantifiable intervention priority.

The condition assessment method developed by the US Army Corps of Engineers [59] establishes two main types of assessment: detailed distress surveys and direct condition ratings. These methods are intended to be used in different scenarios, the latter being faster to use and the former more meticulous. While in detailed distress surveys the surveyor identifies each type of defect detected in a building component, when using direct condition ratings, the surveyor evaluates each component in more general terms. To measure the degradation in detailed distress surveys, each detected defect is classified according to severity levels (low, medium and high), whose criteria are defined for each type of defect in each type of building component. With direct condition ratings, the surveyor assesses each component according to a set of general rating criteria. Three main ratings are defined: green, amber and red, from little to serious serviceability loss due to degradation. Each rating is further subdivided into three categories: high $(+)$, low $(-)$ and middle. Both methodologies are used to compute condition indexes at different levels: component-section, building component, system and building.

Severity ratings of defects are also used in research about a decision-making process to select façade materials minimising potential defects at the design stage [60]. In this situation, severity ratings are used to determine the criticality of defects according to a five-point scale, where the seriousness of defects is assessed. These severity ratings are as follows: extremely minor (1), minor (2), moderate (3), major (4) and extremely major (5). Another scale determines the frequency rating of defects.

Bortolini and Forcada [61] developed a building inspection system for evaluating the technical performance of existing buildings. The third step of that system includes the assessment of the severity of defects using a severity rating associated with the effects of defects and with their urgency of repair. Three levels of severity are determined according to general criteria: severity 1 refers to low impact, severity 2 to moderate impact and severity 3 to severe impact. The assessment results are used to support maintenance recommendations.

The set of individual expert inspection systems developed by the authors' research team at IST-UL includes, in each detailed file of defects, the classification parameters to determine the severity/repair urgency level of each detected defect. These parameters are used to rate defects from level 0 to level 2. Level 0 corresponds to the need for immediate intervention, level 1 to the need for intervention in the medium term, and level 2 to the need for monitoring the progression of the defect. When the set of individual inspection systems was used to develop the global inspection system, where the atlas of defects was included, the three levels were adapted to a five-level scale, considering implicit gravity differences between different building elements/materials, i.e., the effects of defects may be aggravated by the characteristics of some materials. Furthermore, the global inspection system was developed in conjunction with service life prediction models for the same scope of building elements/materials [62]. Those models already included a methodology to determine the severity of degradation of building elements. For this reason, in the global building inspection system, the rating of defects was restricted to the urgency of repair [11].

At IST-UL, a research team has been developing service life prediction methodologies for elements/materials of the building envelope [62]. Those methodologies start by determining the following: the weighted severity of degradation of building elements (\%) according to the area of the building element affected by each defect; that defect's multiplying factor as a function of its condition (from 0 to 4); and the type of defect's weighting coefficient, which corresponds to the relative 
importance of each defect. The obtained severity of degradation is then placed on a discrete scale that qualitatively defines the degradation level. So, two different scales are used: (i) one to determine the detected defects' multiplying factor according to its condition, varying from 0 to 4 , where 0 correspond to very slight degradation and 4 to severe degradation; and (ii) another to define the building elements' degradation level, varying from no visible degradation (level A) to generalised degradation (level E), matching percentages of severity of degradation.

Ruiz et al. [9] studied the optimal metric for condition rating scales. This study tested a representative group of experts on how they would classify 33 different cases of building pathology in building elements through direct assignment, according to a proposed scale with 11 levels of severity. The statistical analysis of the answers allowed determining that the proposed scale needed improvement since only a $32 \%$ probability of correct classification of the phenomena was achieved. Using a clustering algorithm, a five-level scale was determined to provide the lowest standard deviation of the global error. IST-UL's global inspection system also proposes five levels of urgency of repair. Additionally, Ruiz et al. [9] conclude that a catalogue of images of building elements with reference values of severity would be a valuable contribution to classify building pathology, increasing the accuracy of assigning levels of severity of degradation. The proposed atlas of defects is the realisation of such a catalogue.

Table 2 summarises the mentioned scales used to measure the degradation of building elements. The scales' measure, levels and type of use are highlighted.

Table 2. Examples of scales used to measure the degradation of building elements.

\begin{tabular}{|c|c|c|c|}
\hline Reference & Measure & Levels & Use \\
\hline [49] & state of a building component & 1-6 (excellent to very bad) & direct assignment \\
\hline [50] & deterioration state of elements & $\begin{array}{l}\mathrm{a}, \mathrm{b}, \mathrm{c} \text { and } \mathrm{d} \\
\text { (from the least to the most severe) }\end{array}$ & direct assignment \\
\hline [53] & $\begin{array}{l}\text { obsolescence criteria ratings for } \\
\text { elements of office buildings }\end{array}$ & $\begin{array}{c}\text { A, B and C } \\
\text { (from good to poor or not sufficient) }\end{array}$ & algorithm \\
\hline [54] & $\begin{array}{l}\text { condition assessment ratings of } \\
\text { building systems }\end{array}$ & $\begin{array}{c}5,4,3,2 \text { and } 1 \\
\text { (from excellent to bad) }\end{array}$ & direct assignment \\
\hline [55] & $\begin{array}{l}\text { level of severity of degradation } \\
\text { of building elements }\end{array}$ & $\begin{array}{l}3-10 \\
\text { (8 levels, from the most to the least } \\
\text { severe) }\end{array}$ & algorithm \\
\hline [56] & inspected severity of deficiencies & $\begin{array}{l}\quad 0-100 \\
\text { (from the least to the most severe) }\end{array}$ & direct assignment \\
\hline$[57,58]$ & $\begin{array}{l}\text { degradation condition of } \\
\text { building elements }\end{array}$ & $\begin{array}{c}0,1,2 \text { and } 3 \\
\text { (from not visible to } \\
\text { generalised degradation) }\end{array}$ & direct assignment \\
\hline$[57,58]$ & severity of defects & $\begin{array}{c}\mathrm{A}, \mathrm{B}, \mathrm{C}, \mathrm{D} \text { and } \mathrm{E} \\
\text { (from the least to the most severe) }\end{array}$ & direct assignment \\
\hline [59] & $\begin{array}{l}\text { distress severity (detailed } \\
\text { distress survey) }\end{array}$ & low, medium or high & algorithm \\
\hline [59] & $\begin{array}{l}\text { direct rating of serviceability } \\
\text { problems due to degradation }\end{array}$ & $\begin{array}{c}\text { from Green }(+) \text { to Red }(-) \\
\text { (9 levels, from the least to the } \\
\text { most severe) }\end{array}$ & direct assignment \\
\hline [60] & $\begin{array}{l}\text { severity rating (seriousness) } \\
\text { of defects }\end{array}$ & $\begin{array}{c}1,2,3,4 \text { and } 5 \\
\text { (from extremely minor to } \\
\text { extremely major) }\end{array}$ & direct assignment \\
\hline [61] & $\begin{array}{l}\text { severity rating of defects (effects } \\
\text { and urgency of repair) }\end{array}$ & $\begin{array}{c}1,2 \text { and } 3 \\
\text { (from low to severe impact) }\end{array}$ & direct assignment \\
\hline $\begin{array}{c}{[8,11,14,16,18} \\
19,21,25,27,29- \\
31]\end{array}$ & $\begin{array}{l}\text { severity/repair urgency level } \\
\text { of defects }\end{array}$ & $\begin{array}{c}0,1 \text { and } 2 \\
\text { (from the most to the least severe) }\end{array}$ & algorithm \\
\hline [62] & defects' condition & $\begin{array}{l}\quad 0,1,2,3 \text { and } 4 \\
\text { (from the least to the most severe) }\end{array}$ & algorithm \\
\hline [62] & $\begin{array}{l}\text { severity of degradation of } \\
\text { building elements }\end{array}$ & $\begin{array}{c}\mathrm{A}, \mathrm{B}, \mathrm{C}, \mathrm{D} \text { and } \mathrm{E} \\
\text { (from the least to the most severe) }\end{array}$ & algorithm \\
\hline [9] & $\begin{array}{l}\text { severity of degradation of } \\
\text { building elements }\end{array}$ & $\begin{array}{l}0,1,2,3 \text { and } 4 \\
\text { (from the least to the most severe) }\end{array}$ & direct assignment \\
\hline
\end{tabular}




\section{Materials and Methods}

Considering the objective of creating a catalogue to ease matching building degradation phenomena with defects in a classification list and with a level of urgency of repair, a database was devised for reference during fieldwork. Previously developed components of the global building inspection system were used, namely the classification list of defects [11] and the detailed files of defects, where the urgency of repair was characterised.

First, the structure of such a database was designed. The atlas of defects has several pages, each corresponding to a defect listed in the classification of defects of the global building inspection system. Each page is arranged as a table with columns corresponding to types of building elements/materials and rows to levels of urgency of repair. The number of columns varies according to the field of application specified in the detailed file of the defect (Figure 1). The levels of urgency of repair are also established in the files of defects (Figure 1), varying from 0 to 4 , where level 0 is the most urgent and level 4 the least urgent. So, the table has five rows. In each cell of each page's table, an exemplifying photograph and a concise description are available, establishing the criteria to identify a defect in a type of building element/material with a specific level of urgency of repair.

\begin{tabular}{c}
\hline File of defect \\
A-B4 Blistering/bulging \\
\hline
\end{tabular}
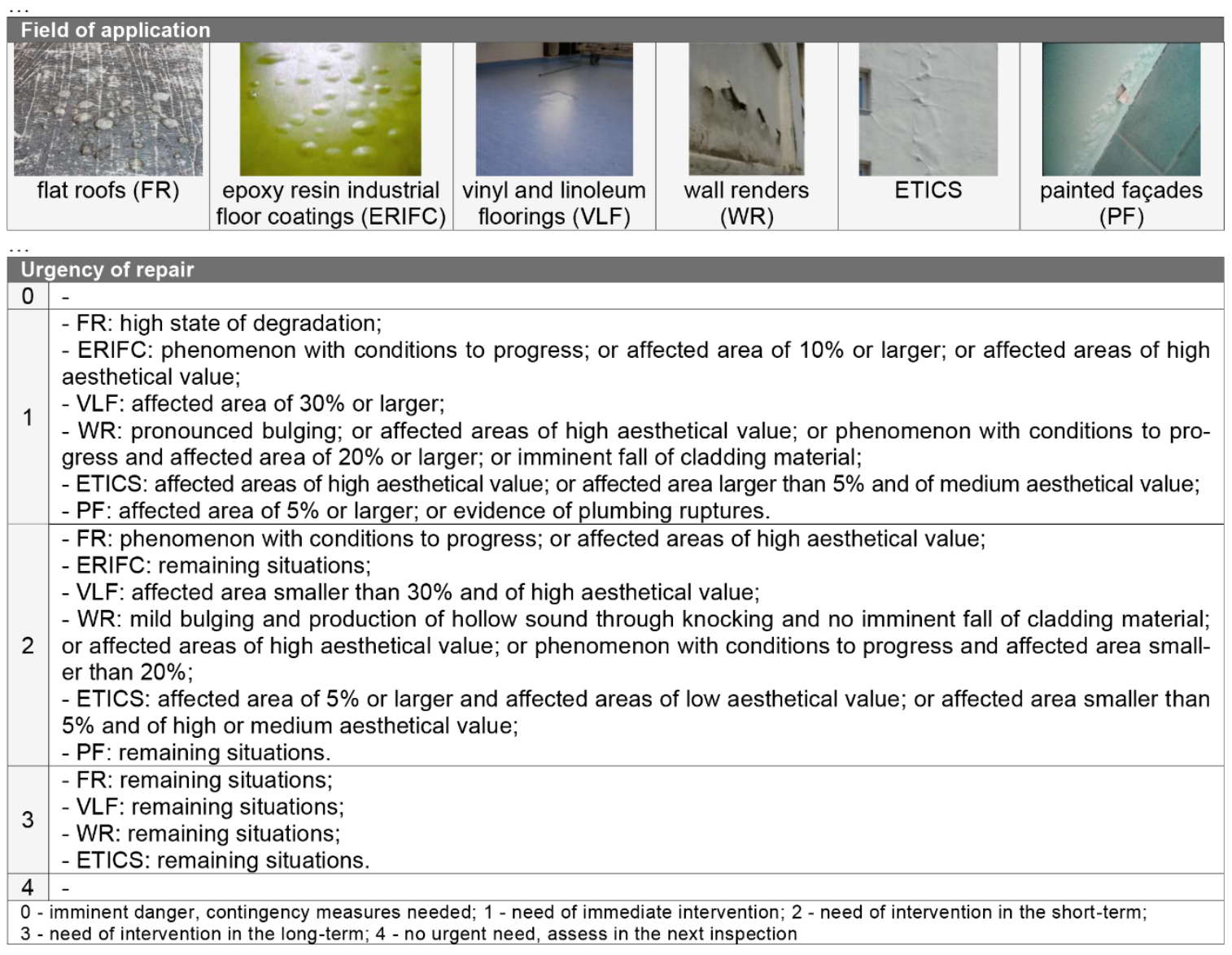

Figure 1. Excerpt of the detailed file of defect "A-B4 Blistering/bulging" showing the fields "field of application" and "urgency of repair".

The levels of urgency of repair are defined as follows [11]:

- $\quad 0$ : imminent danger, contingency measures needed; 
- $\quad$ 1: need for immediate intervention;

- 2: need for intervention in the short-term;

- 3: need for intervention in the long-term;

- 4: no urgent need, assess in the next inspection.

During fieldwork, the surveyor attributes a level of urgency of repair to each detected defect based on the application of algorithms. In other words, each level of urgency of repair corresponds to a set of conditions determined for each type of building defect according to the type of building element/material.

With the structure of the atlas of defects laid down (Figure 2), all the pages were filled with graphical and descriptive contents. The photographic content of the atlas of defects was collected from the authors' research team, mainly from inspection campaigns, or taken specifically to fill the atlas of defects.

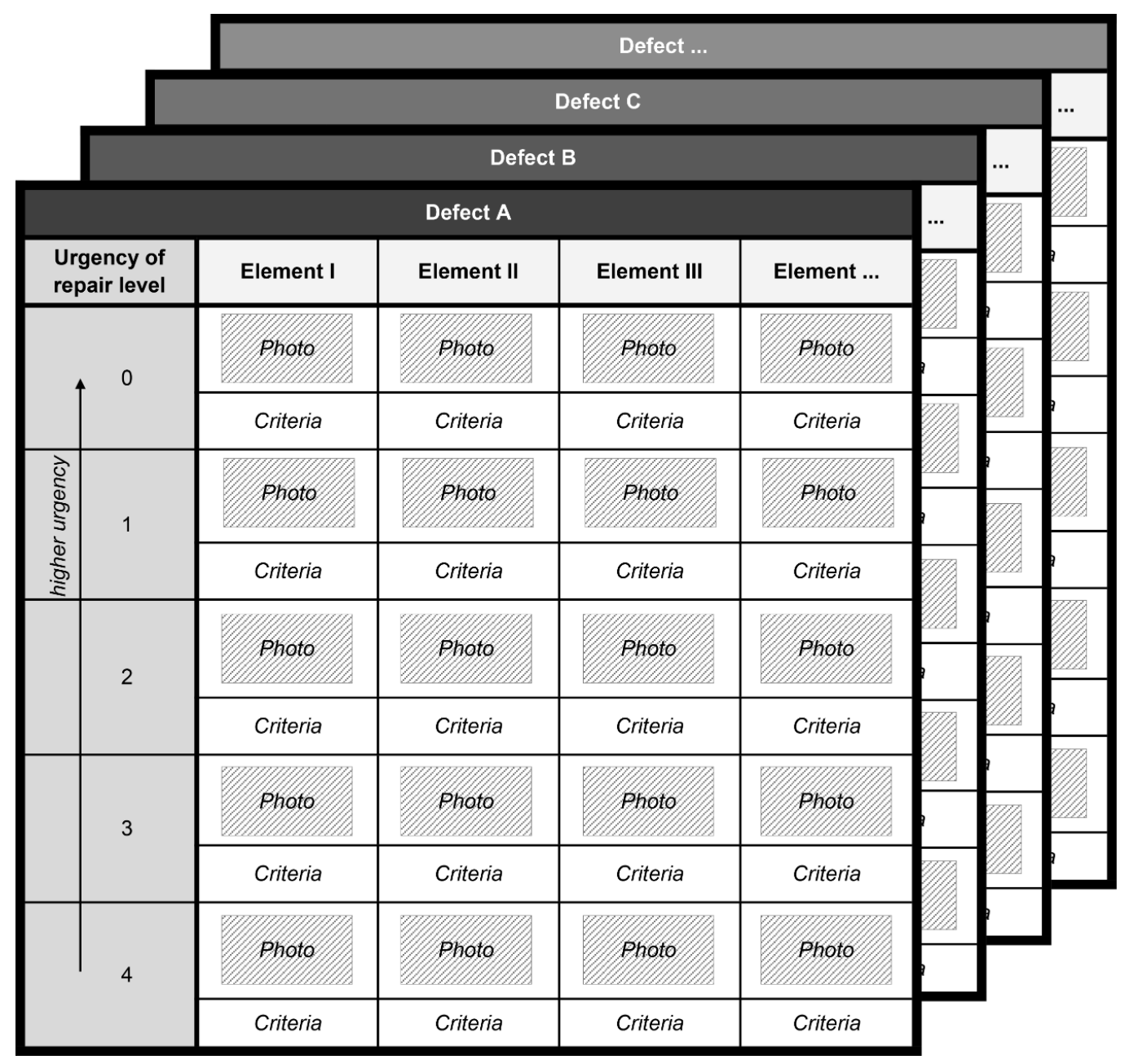

Figure 2. Structure of the atlas of defects.

\section{Results}

Figures 3 and 4 show excerpts of the atlas of defects of the global building inspection system. Figure 3 partially shows the page of defect "A-A3 Dirt and accumulation of debris" with columns corresponding to external claddings of pitched roofs, door and window frames, and wall renders. Figure 4 shows a part of the page of defect "A-C2 Oriented cracking on the current surface", presenting the columns for adhesive ceramic tiling, natural stone claddings and architectural concrete surfaces. 


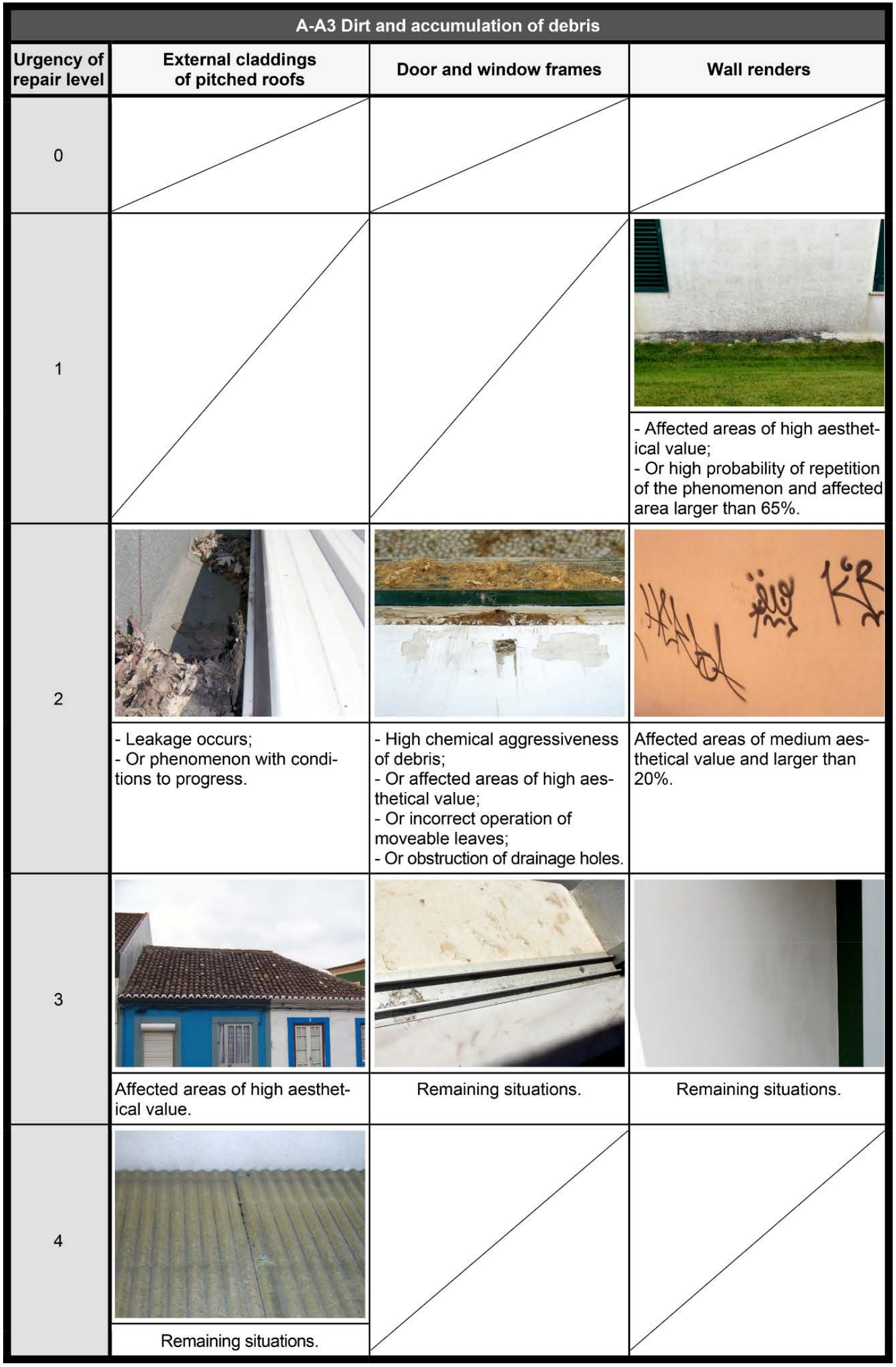

Figure 3. Excerpt of the atlas of defects: page of defect "A-A3 Dirt and accumulation of debris" with columns corresponding to three different types of building elements/materials. 


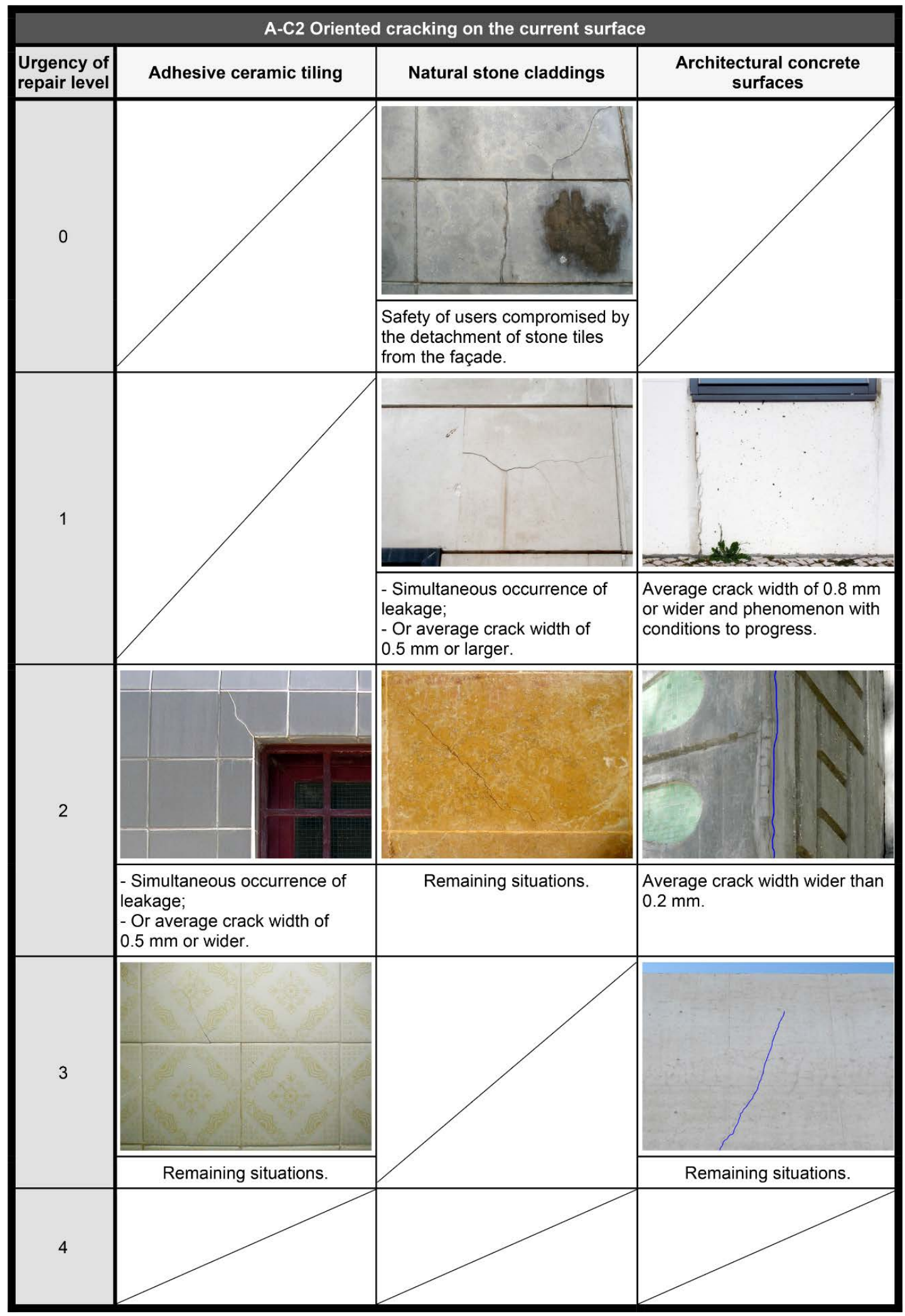

Figure 4. Excerpt of the atlas of defects: page of defect "A-C2 Oriented cracking on the current surface" with columns corresponding to three different types of building elements/materials.

Figures 3 and 4 show that not all levels of urgency of repair apply to a type of defect in every type of building element/material. For instance, in Figure 3, for external claddings of pitched roofs, 
only levels 2, 3 and 4 are defined. In the same figure, for door and window frames, only levels 2 and 3 are determined. This is associated with the effects of a defect in different building elements/materials. In these cases, "dirt and accumulation of debris" (A-A3) in claddings of pitched roofs or in door and window frames is considered to only result in interventions in the short term in the most urgent cases, as this defect does not usually raise safety concerns. In pitched roofs, lighter cases of dirt and accumulation of debris are even considered to only require monitoring in subsequent inspections (level 4).

However, in the case of "Oriented cracking on the current surface" (A-C2) on natural stone claddings, defects may go from levels 0 to 2 of urgency of repair (Figure 4). The occurrence of cracks on natural stone claddings is considered to endanger users and passers-by in severe situations, requiring contingency measures (level 0).

Considering the number of types of defects (38) included in the corresponding classification list and the (varying) number of building elements/materials each one applies to, the atlas of defects has a total of 179 columns (combination defect-building element/material). Of the latter, $94 \%$ are filled in the row corresponding to level 2 of urgency of repair, while only $1 \%$ are filled in the row corresponding to level 4. The row of level 0 is also sparsely filled, with only $13 \%$ of columns filled. Levels 1,2 and 3 are those more often defined for defect-building element/material combinations, with rows filled in more than $50 \%$ of columns.

Additionally, out of the 23 defect-building element/material combinations that are defined in level 0, $14(61 \%)$ refer to defects occurring in natural stone claddings. The possibility of detachment of a stone slab from a façade is regarded as a menace to the safety of passers-by due to its weight, thus increasing the prospective level of urgency of repair of defects on natural stone claddings.

Observing the descriptive contents of Figures 3 and 4, different types of criteria may be distinguished. Some refer to the simultaneous occurrence of other defects (e.g., leakage), some to the context of the defect (e.g., the aesthetical value of affected areas), some to the characteristics of the defect (e.g., extent) and others to the effects of the defect (e.g., safety issues). Many criteria are not identifiable through exemplificative photographs. It is the case of the phenomenon's conditions to progress, aesthetical value of the affected areas, safety risks for passers-by and percentage quantification of the affected area.

A phenomenon's conditions to progress can only be conclusively analysed on-site. Data like temperature, relative humidity, aggressiveness of the environment and maintenance means, among others, should be taken into account. They may be recorded for off-site assessment, but at least one visit to the site under inspection is required. Some signs of this type of data may be identified in photographs, but they generally go beyond the visual information (e.g., a cloudy photograph may not correspond to low temperatures). Therefore, non-visual information should be taken into account while reading the atlas of defects (e.g., Figure 3, level 2 of "A-A3 Dirt and accumulation of debris" in external claddings of pitched roofs).

The aesthetical value of the affected areas is generally determined by the importance of the façade, roof or flooring in the context of the building. Typically, in current buildings, the front façade has high aesthetical value due to being adjacent to a public street and encompassing the main entrance to the building, while side and rear façades normally have medium and low aesthetical value, respectively. Since the photographs that illustrate the atlas of defects tend to focus on the pathological phenomena, the aesthetical value of the building elements where they are detected is not obvious. This is the case in the pictures illustrating the column of wall renders in Figure 3. If the case of "Dirt and accumulation of debris" (A-A3), illustrating level 3 of urgency of repair in wall renders, occurred on the front façade of the building, it would then be considered of level 1, thus requiring immediate intervention, instead of intervention in the long-term.

As for safety risks for passers-by, the criteria to determine the urgency of repair of some defects in some building elements/materials may refer to slippery floorings, risk of stumbling or the possibility of elements detaching and falling from façade claddings (as proposed by the system of evaluation 
of façades of Ruiz et al. [63]). These occurrences are not usually evident in photographs, being identified through a tactile assessment or depending on the height of the phenomenon. For instance, the possibility of a ceramic tile falling from a façade is associated with different safety risks according to the height of the defect: risks are lower immediately above the floor than at $10 \mathrm{~m}$ high. Still, that height is not usually understandable in photographs centred on defects. So, the unclear expression of safety risks needs to be considered while referring to the atlas of defects. This is the case in the picture illustrating the occurrence of "Oriented cracking on the current surface" (A-C2) on a natural stone cladding with level 0 of urgency of repair (Figure 4).

The percentage quantification of the affected area is a characteristic of the defect that depends not only on its extent but also on the extent of the whole surface. Although it is possible to estimate the absolute area affected by the defect, whether using on-site measurements or reference elements in the photograph (like tiles or windows with known size), the whole surface where the defect occurs is not usually visible in defect-centred photographs. For that reason, pictures like those illustrating the column of wall renders in Figure 3 do not provide all the information needed to determine the urgency of repair of situations of "Dirt and accumulation of debris" (A-A3).

In short, the usefulness of the atlas of defects depends on the inseparable combination of exemplifying photographs with descriptive criteria.

Moreover, it should be stressed that the same defect may manifest itself in different ways, even in the same type of building element/material (e.g., different fungi). In its current state, the atlas of defects is not an exhaustive catalogue of all possible forms of defects.

\section{Discussion}

Considering the excerpts of the atlas of defects presented in Figures 3 and 4, cases of defects "A-A3 Dirt and accumulation of debris" and "A-C2 Oriented cracking on the current surface" may be analysed and classified in terms of urgency of repair.

Figure 5 shows three different window frames affected by "Dirt and accumulation of debris" (A-A3). The window frames in Figure $5 \mathrm{a}, \mathrm{b}$ are of anodised aluminium and the one in Figure $5 \mathrm{c}$ of reinforced concrete. To determine the urgency of repair of each window frame, the criteria determined in the atlas of defects should be analysed, starting at the most urgent level of repair, which is level 2, for door and window frames (Figure 3). In Figure 5, none of the observed debris has high chemical aggressiveness. In terms of aesthetical value, the window in Figure $5 b$ is located on a front façade, thus having high aesthetical value. The observance of this criterion alone makes this a case of level 2 of urgency of repair, even though only a white spot of paint is observed in the window frame. As for the incorrect operation of moveable leaves, Figure $5 b$, c show fixed windows, but Figure 5a shows a sliding window, where the accumulation of debris next to the sliding guides probably hinders the movement of the leaves and prevents them from shutting completely. So, the case in Figure 5a is also of level 2 of urgency of repair. This case also shows obstruction of the drainage holes of the window frame, which reinforces the need for intervention in the short-term (level 2). The case in Figure $5 c$ does not match any of the criteria stated for level 2 and thus is considered a situation with level 3 of urgency of repair. It is interesting to conclude that both cases in Figure $5 a, b$ have the same level of urgency of repair while being so different, with the debris of Figure $5 \mathrm{a}$ appearing to be much more worrying. If considered in the classification parameters, the aesthetical value of the affected areas may be very influential. 


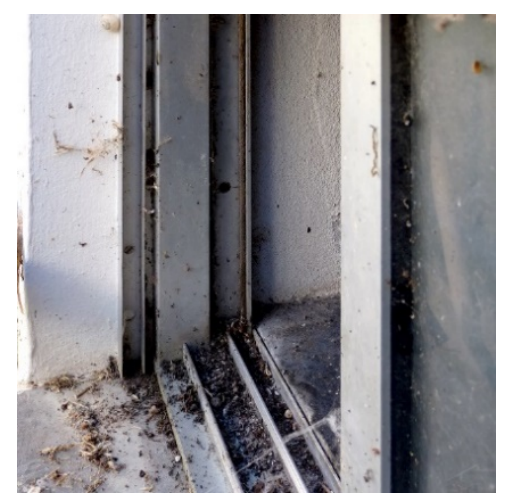

(a)

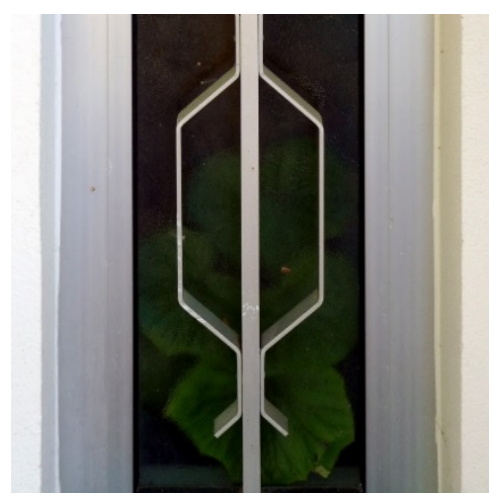

(b)

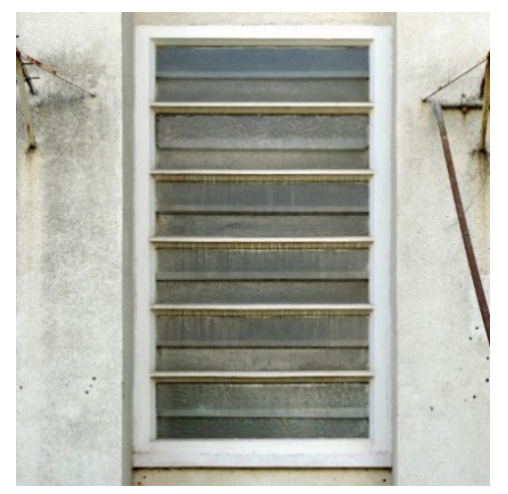

(c)

Figure 5. Cases of defect "A-A3 Dirt and accumulation of debris" in window frames: (a) accumulation of debris affecting the operation of moveable leaves and obstructing drainage holes; (b) dirt in a window frame on a front façade; (c) dirt in a window frame on a rear façade.

Accumulation of debris is also a factor considered by Fernandes et al. [64] to determine the degradation level of window frames. The accumulation of debris is considered to have a low impact on the overall degradation condition of window frames, thus being associated with a weighting coefficient of 0.1. Furthermore, whether this defect affects sealings, fittings or framework materials and coatings, it is always rated as level 1 of defect condition (from 0 to 4 , from the least to the most severe), even if the accumulation of debris affects more than $20 \%$ of the component. An assessment of the defect's effects is taken into account, considering that corrective cleaning operations can eliminate this defect and regular cleaning may prevent its reoccurrence. Still, Fernandes et al.'s [64] approach does not invalidate the urgency of repair approach, as the low impact of a defect's effects in terms of degradation does not contradict the importance of eliminating such defect, even more so when the defect may cause other damages in the future.

Figure 6 presents six cases (a-f) of "A-A3 Dirt and accumulation of debris" on wall renders. Two cases per building are shown: Figure $6 \mathrm{a}, \mathrm{b}$ occur in the same building, Figure $6 \mathrm{~d}$,e occur in another building and Figure $6 \mathrm{c}, \mathrm{d}$ occur in yet another building. For wall renders, defect A-A3 is classified from levels 1 to 3 of repair urgency (Figure 3). As for window frames, to assign a level of urgency of repair to each case in Figure 6, they must be analysed in light of the criteria determined for each level, starting from the most urgent one. So, if the affected areas are of high aesthetical value, level 1 applies, which is the case in Figure 6a,f. Then, situations with an affected area larger than $65 \%$ of the surface and high probability of repetition of the phenomenon are also considered as level 1 of urgency of repair. Figure $6 \mathrm{~d}$ observes these criteria, with about $77 \%$ of the surface affected by the accumulation of dirt associated with a thermophoresis phenomenon and no measures implemented to stop the defect from progressing. If the affected areas are of medium aesthetical value and larger than $20 \%$ of the rendered surface, they should be classified within level 2 of urgency of repair. Figure $6 c, e$ occur on side façades, thus having medium aesthetical value, but only the affected area of Figure 6e represents more than $20 \%$ of the rendered surface (about $58 \%$ ). So, Figure 6e requires intervention in the short-term (level 2). The remaining situations, i.e., Figure $6 b, c$, are of level 3 of urgency of repair, as their characteristics do not match any of the parameters defined for levels 1 and 2.

Summing up, the urgency of repair of cases in Figure 6 is as follows:

- Figure 6a: level 1;

- Figure 6b: level 3;

- Figure 6c: level 3;

- $\quad$ Figure 6d: level 1;

- Figure 6e: level 2; 
- $\quad$ Figure 6f: level 1.

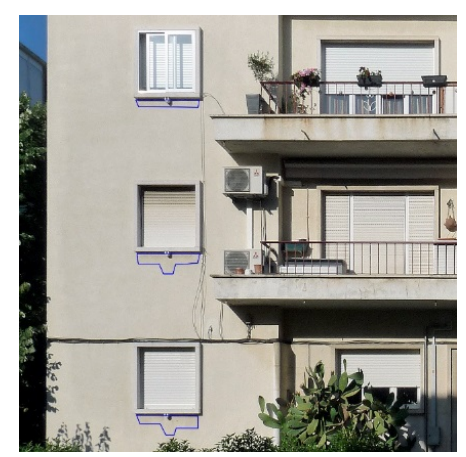

(a)

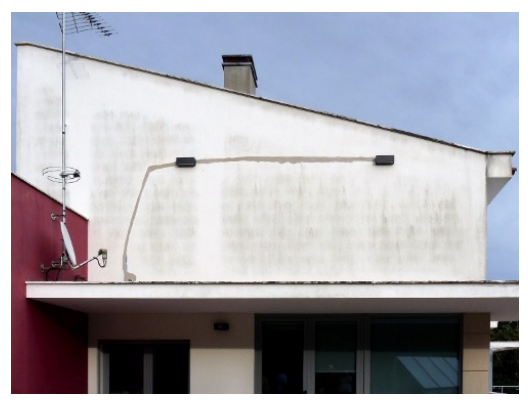

(d)

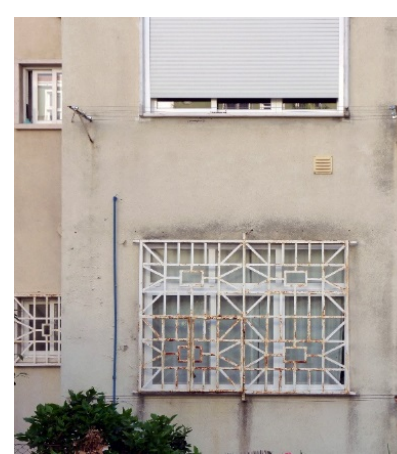

(b)

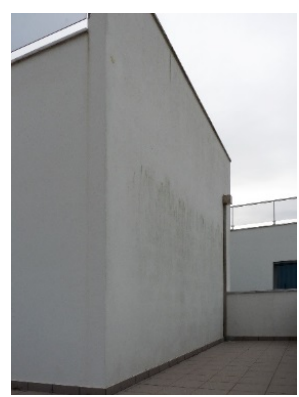

(e)

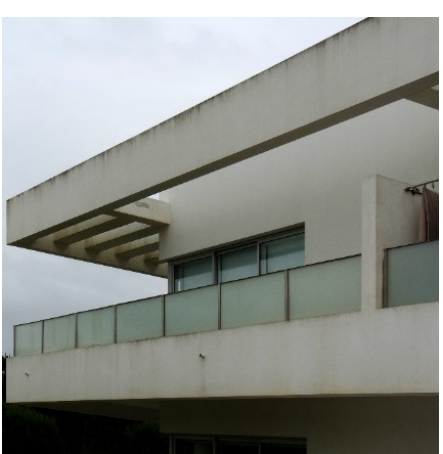

(c)

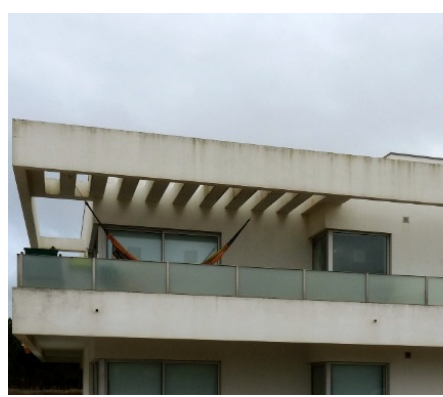

(f)

Figure 6. Cases of defect "A-A3 Dirt and accumulation of debris" on wall renders: (a) dirt below windowsills on a front façade, (b) dirt on a rear façade, (c) dirt on a side façade, (d) dirt on a rear façade, (e) dirt on a side façade, (f) dirt on a front façade.

Once again, the criterion associated with the aesthetical value of the affected areas is decisive. For instance, Figure $6 c, f$ have identical characteristics, but the importance of Figure $6 f$, showing the front façade, which is adjacent to the public street and forms a uniform set of façades that frames that street, determines that, when prioritising the repairs, this case should be repaired first.

The analysis of van Hees et al. [65] of the damage of old mortars systematises the factors affecting the mortars' degradation processes. Of those, some may be highlighted for affecting the development of "Dirt and accumulation of debris" (A-A3) in the cases shown in Figure 6. In terms of environmental factors, the moisture supply and the air pollution impact all the mentioned cases. Furthermore, the moisture supply, in these cases, is associated with rain runoff and surface water. In Figure $6 \mathrm{c}, \mathrm{f}$, the effect of rainwater runoff is more evident as no coping/capping stone/flashing is observed on the top of the rendered surfaces. As wet-dry cycles occur successively, different types of dirt particles tend to accumulate on the wet surface of the rendered façade [66]. So, a design factor is also associated with these cases of degradation (detailing of the building) [65]. On the other hand, in Figure 6a, the differential washing effect of rainwater affects the façade below windowsills. When rainwater reaches a façade, the water flow over the surface carries dirt particles, washing them off. Some areas of the façade are not affected by this phenomenon and keep accumulating dirt [66]. Moreover, in Figure 6d,e, dirt accumulates on areas where water condensation occurs. This is called a thermophoresis phenomenon, which is associated with poor thermal insulation conditions [67]. Additionally, the lack of maintenance and the properties of the mortar system may affect the degradation processes in Figure 6. The porosity of materials may also affect the accumulation of dirt on the façades [65]. 
Looking now at instances of defect "A-C2 Oriented cracking on the current surface", Figure 7 shows four situations of oriented cracking on architectural concrete surfaces. Analysing the criteria to define the urgency of repair, in Figure 4, the main classification parameter is the average crack width. Although a crack width ruler was not used in the photographs in Figure 7, due to the elevated position and consequent lack of access to the cracks within the façades, other elements may be considered as size references, such as bug holes, fastening marks or panel/casting joints. Two criteria have to be met to include an oriented cracking phenomenon in architectural concrete surfaces in the level 1 set (need for immediate intervention): (i) the average crack width must be $0.8 \mathrm{~mm}$ or wider, and (ii) the defect must have conditions to progress. Considering that the exposure conditions of all cases in Figure 7 remain unchanged, all cases meet the second criterion. As for the crack width, Figure $7 \mathrm{a}, \mathrm{b}$ show clearly wider cracks than Figure 7c,d. Therefore, the former should be accounted for as level 1 of urgency of repair. A-C2 occurrences in architectural concrete surfaces belong to level 2 of urgency of repair when the average crack width is greater than $0.2 \mathrm{~mm}$ (and thinner than $0.8 \mathrm{~mm}$ ). Careful analysis of Figure $7 \mathrm{c}, \mathrm{d}$ allows discovering some differences between them, the most important being that the crack in Figure $7 \mathrm{c}$ is better defined throughout its length, while the crack in Figure $7 \mathrm{~d}$ almost disappears in some places. Although the analysis of the threshold is not very precise and is more comparative in nature, given the provided data, Figure $7 \mathrm{c}$ should be rated as level 2 and Figure $7 \mathrm{~d}$ as level 3 of urgency of repair.

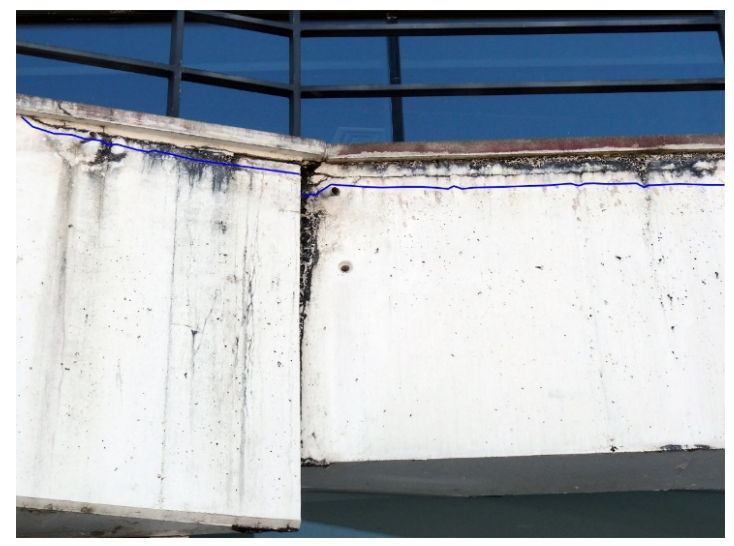

(a)

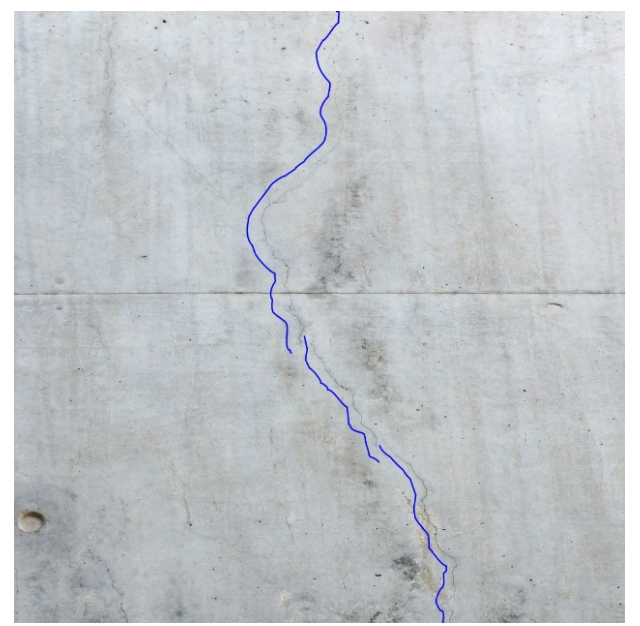

(c)

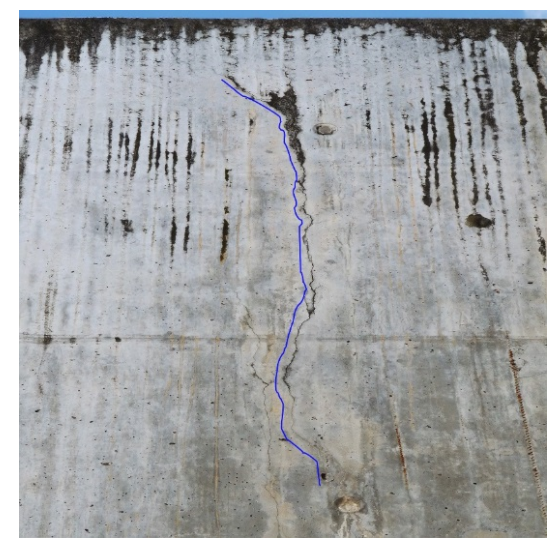

(b)

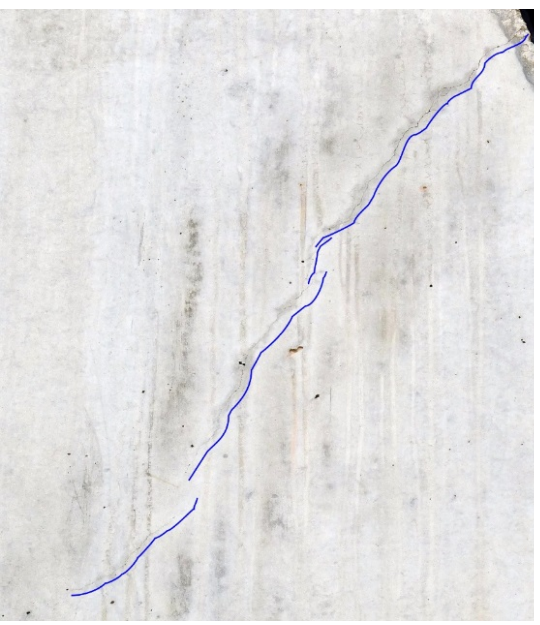

(d)

Figure 7. Cases of defect "A-C2 Oriented cracking on the current surface" in architectural concrete surfaces. 
Figure 7a-d all show different cases of defect "A-C2 Oriented cracking on the current surface" in architectural concrete surfaces. As the explanation would be the same for all, only a general explanation was provided.

The National Precast Concrete Association [68] also suggests thresholds to classify the width of cracks on architectural concrete. Three types of cracks are proposed-fine, medium and wide-with the following width ranges (original values are provided in inches): fine cracks are less than 0.25 mm wide, medium cracks are between $0.25 \mathrm{~mm}$ and $1.01 \mathrm{~mm}$ wide and wide cracks are more than $1.01 \mathrm{~mm}$ wide. This classification is only slightly different from that proposed in Figure 4, not changing significantly the assessment of cracking phenomena in Figure 7.

In Figure 8, three different cases of "Oriented cracking on the current surface" (A-C2) on adhesive ceramic tiling are observed. These cases may be rated according to the levels of urgency of repair defined in the atlas of defects (Figure 4); for adhesive ceramic tiling, only levels 2 and 3 are set for defect A-C2. Oriented cracking occurrences may be of level 2 of urgency of repair if one out of two conditions is observed: (i) simultaneous occurrence of leakage; or (ii) average crack width of $0.5 \mathrm{~mm}$ or greater. All the other occurrences are accounted for as level 3. Again, no crack width ruler was used to measure the cracks in Figure 8, but the size of movement joints and other elements in the pictures may be used as a reference. Figure $8 \mathrm{c}$ shows almost imperceptible and very thin cracks. This occurrence does not meet any level 2 criteria, thus being classified as level 3 of urgency of repair. As for Figure 8a,b, Figure 8a appears to show wider cracking, but both cases present cracks wider than $0.5 \mathrm{~mm}$. Additionally, Figure 8a also shows signs of leakage through the crack.

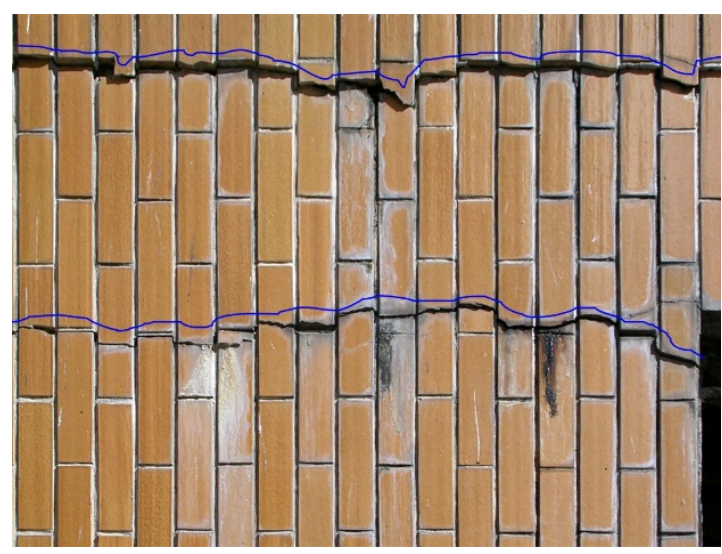

(a)

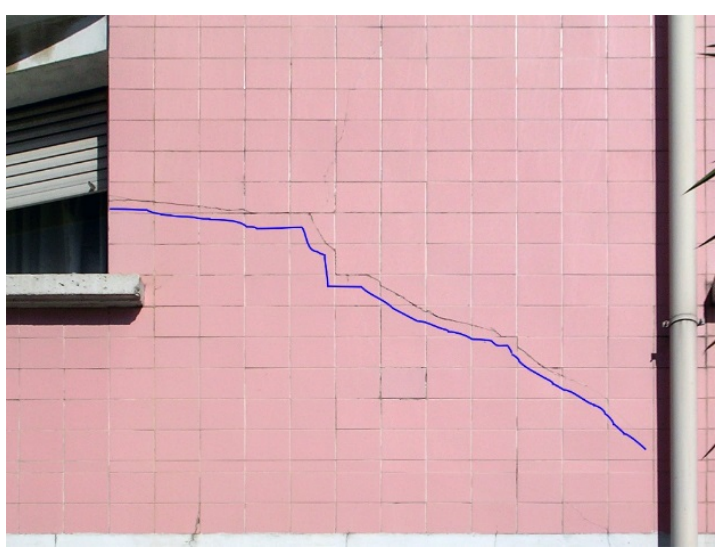

(b)

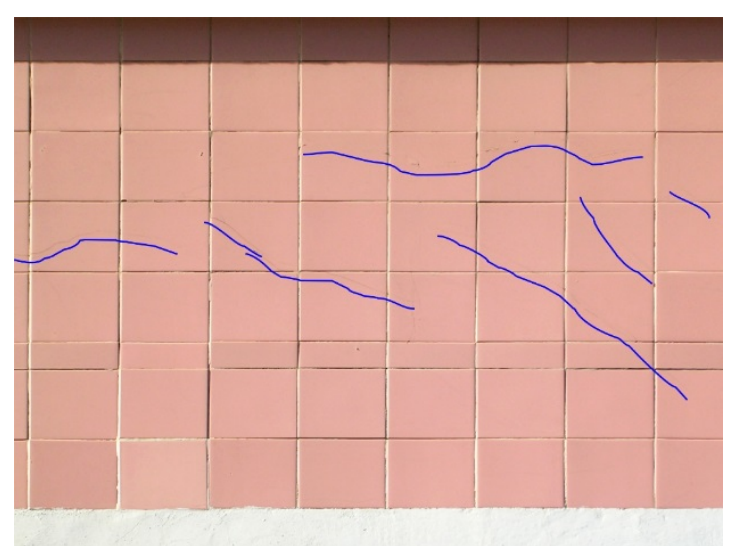

(c)

Figure 8. Cases of defect "A-C2 Oriented cracking on the current surface" in adhesive ceramic tiling. 
Figure 8a-c all show different cases of defect "A-C2 Oriented cracking on the current surface" in adhesive ceramic tiling. As the explanation would be the same for all, only a general explanation was provided.

Cracking phenomena in adhesive ceramic tiling are analysed by Gaspar [69]. They may be caused by expansion and shrinkage phenomena affecting the bedding material and, consequently, the tile-mortar interface. The different coefficients of expansion of materials used in the substrate cause shear and tensile stresses that may cause failure. This may be the case in Figure 8a. Additionally, the significant width of the crack may cause water seepage, resulting in subsequent damage.

The exercise of attributing an urgency-of-repair level to each case in Figures 5-8 may be extended to using other scales for comparison purposes. The methodological approach of Ruiz et al. [9], optimising the metric of a condition rating scale, justifies adopting that scale in this comparative analysis. The scale proposed by Ruiz et al. [9] establishes five grades of severity of degradation of building elements for direct assignment, namely null (0), mild (1), moderate (2), high (3) and extreme (4). Transposing the definition of each severity grade of building elements to building defects, the results in Table 3 are obtained. To compare the grades attributed using the scale of the atlas of defects and the one proposed by Ruiz et al. [9], a third scale is necessary, unifying the descendant direction of urgency of repair/severity of degradation. In the unified scale, the most urgent/severe level is level I, as opposed to level V, which is the least urgent/severe. The unified grades equivalent to the urgency-of-repair grade and the severity grade are shown between brackets in each column of Table 3.

Table 3. Comparison of urgency-of-repair levels with grades of severity.

\begin{tabular}{|c|c|c|c|c|}
\hline \multicolumn{2}{|c|}{ Cases of Defects } & $\begin{array}{l}\text { Urgency of Repair } \\
\text { (Atlas of Defects) }^{1}\end{array}$ & $\begin{array}{l}\text { Severity Grade } \\
\text { (Ruiz et al. [9]) }^{2}\end{array}$ & $\begin{array}{c}\text { Comparison Using a } \\
\text { Unified Scale }{ }^{3}\end{array}$ \\
\hline \multirow{3}{*}{ Figure 5} & $\mathrm{a}$ & 2 (III) & 3 (II) & \multirow{3}{*}{$\begin{array}{l}\text { one level difference } \\
\text { one level difference } \\
\text { one level difference }\end{array}$} \\
\hline & $\mathrm{b}$ & 2 (III) & 1 (IV) & \\
\hline & c & 3 (IV) & 2 (III) & \\
\hline \multirow{6}{*}{ Figure 6} & $\mathrm{a}$ & 1 (II) & $1(\mathrm{IV})$ & \multirow{6}{*}{$\begin{array}{c}\text { two levels difference } \\
\text { one level difference } \\
\text { match } \\
\text { one level difference } \\
\text { match } \\
\text { two levels difference }\end{array}$} \\
\hline & $\mathrm{b}$ & 3 (IV) & 2 (III) & \\
\hline & $\mathrm{C}$ & 3 (IV) & 1 (IV) & \\
\hline & $\mathrm{d}$ & 1 (II) & 2 (III) & \\
\hline & e & 2 (III) & 2 (III) & \\
\hline & $\mathrm{f}$ & 1 (II) & 1 (IV) & \\
\hline \multirow{4}{*}{ Figure 7} & $\mathrm{a}$ & 1 (II) & 3 (II) & \multirow{4}{*}{$\begin{array}{c}\text { match } \\
\text { one level difference } \\
\text { one level difference } \\
\text { match }\end{array}$} \\
\hline & $b$ & 1 (II) & 2 (III) & \\
\hline & $\mathrm{c}$ & 2 (III) & 1 (IV) & \\
\hline & $\mathrm{d}$ & 3 (IV) & 1 (IV) & \\
\hline \multirow{3}{*}{ Figure 8} & $\mathrm{a}$ & 2 (III) & 3 (II) & \multirow{3}{*}{$\begin{array}{l}\text { one level difference } \\
\text { match } \\
\text { match }\end{array}$} \\
\hline & $\mathrm{b}$ & 2 (III) & 2 (III) & \\
\hline & c & 3 (IV) & 1 (IV) & \\
\hline
\end{tabular}

${ }^{1} 0$ : imminent danger, contingency measures needed; 1 : need for immediate intervention; 2 : need for intervention in the short term; 3 : need for intervention in the long term; 4 : no urgent need, assess in the next inspection. ${ }^{2} 0$ : null severity; 1: mild severity; 2: moderate severity; 3 : high severity; 4: extreme severity [9]. ${ }^{3}$ A unified scale was used for comparison purposes, ranging from I to $\mathrm{V}$, where level $\mathrm{I}$ is the most urgent/severe and level $\mathrm{V}$ is the least.

The last column of Table 3 analyses the difference and correspondence between grades. Levels I and V are not identified in either scales. Only four grades (out of 16) are a match in both scales, with no common denominator, as two are in level IV, one in level III and one in level II. Two cases show more marked differences between grades according to different scales: Figure 6a,f. In both cases, the aesthetical value of the façades determined the classification of defects in level 1 of urgency of repair. So, when confronted with a scale that only assesses the degradation conditions, disregarding other contextual limitations, the severity of these cases is relieved, as only mild signs of "Dirt and 
accumulation of debris" (A-A3) are observed. This comparison highlights the conceptual differences between urgency of repair and severity of degradation [11].

\section{Conclusions}

Considering the question that resulted in the presented research (how can an expeditious tool to identify defects and their urgency of repair be achieved?), this paper has demonstrated that it is possible to develop a catalogue of defects for the non-structural building envelope, taking into account (i) a well-defined classification of defects; (ii) a predetermined scope of building elements/materials; and (iii) a scale of urgency-of-repair levels, whose classification is determined by specific criteria. The atlas of defects combines visual and descriptive contents, aiming at a simple identification approach, easy to use during fieldwork.

The proposed atlas of defects may be used by surveyors during technical inspections. Furthermore, occasional surveyors, like architects and engineers, may also benefit from a tool like the atlas of defects when performing building assessments. Technical building inspections are used in several situations, like within maintenance plans, before deciding on retrofitting or rebuilding options, at the design stage (retrofitting) and to assess insurance claims. Additionally, researchers may use the proposed tool.

The use of such an atlas of defects is expected to help achieve a more reliable diagnosis of building defects, with a more accurate and intuitive identification of the type of defects and their level of urgency of repair. In turn, that improved reliability should improve the effectiveness of maintenance and repair actions, thus prolonging the service life of building elements at lower costs.

The atlas of defects that is proposed was developed within a global building inspection system, but, with the presented methodology, other atlases may be developed within different systems, given the basic materials and, most importantly, a well-defined scope and classification systems (of defects and urgency of repair or others). Although the proposed atlas is focused on non-structural building elements, its layout may be extrapolated to structural building elements.

To the best of the authors' knowledge, there is no such catalogue of building defects and respective urgency of repair in the literature. Furthermore, the need for the proposed atlas of defects has been identified by previous research [9].

In the future, the atlas of defects may be improved with further photographs representing a wider variety of significant situations within the same type of defect and building element/material.

Furthermore, the whole building inspection system will be computerised, including the atlas of defects. That step will provide an advantage in terms of developing a building pathology database, which may be useful in the context of maintenance plans and research. The visual aid of the atlas of defects represents an advantage in terms of swiftness of identification and characterisation. Moreover, the criteria to determine the urgency of repair may be included in algorithms, and the user of the computerised inspection system may only need to answer some simple questions.

Author Contributions: Conceptualization, J.d.B.; methodology, C.P., J.d.B. and J.D.S.; software, C.P.; validation, C.P.; formal analysis, C.P.; investigation, C.P.; resources, C.P., J.B., J.D.S. and I.F.-C.; data curation, C.P.; writing-original draft preparation, C.P.; writing-review and editing, J.B., J.D.S. and I.F.-C.; visualization, C.P.; supervision, J.d.B., J.D.S. and I.F.C.; project administration, J.B.; funding acquisition, J.B. All authors have read and agreed to the published version of the manuscript.

Funding: This research was funded by Fundação para a Ciência e a Tecnologia (FCT), grant number PTDC/ECI-CON/29286/2017, and also by FCT, grant number SFRH/BD/131113/2017.

Acknowledgments: The authors gratefully acknowledge the support of CERIS, from IST-UL.

Conflicts of Interest: The authors declare no conflict of interest. The funders had no role in the design of the study; in the collection, analyses, or interpretation of data; in the writing of the manuscript, or in the decision to publish the results. 


\section{References}

1. Kohler, N.; Yang, W. Long-Term management of building stocks. Build. Res. Inf. 2007, 35, 351-362. [CrossRef]

2. Palmer, R.D. Maintenance Planning and Scheduling Handbook, 2nd ed.; McGraw Hill: New York, NY, USA, 2006; Volume 111, ISBN 007150155X.

3. Flores-Colen, I.; de Brito, J. A systematic approach for maintenance budgeting of buildings façades based on predictive and preventive strategies. Constr. Build. Mater. 2010, 24, 1718-1729. [CrossRef]

4. Flores-Colen, I.; de Brito, J. Discussion of proactive maintenance strategies in façades' coatings of social housing. J. Build. Apprais. 2010, 5, 223-240. [CrossRef]

5. de Brito, J.; Pereira, C.; Silvestre, J.D.; Flores-Colen, I. Expert Knowledge-Based Inspection Systems. Inspection, Diagnosis and Repair of the Building Envelope; Springer: Cham, Switzerland, 2020; ISBN 9783030424459.

6. Robertsen, E. Design for durability-A practical approach. In Durability of Building Materials and Components 8; Lacasse, M.A., Vanier, D.J., Eds.; Institute for Research in Construction: Ottawa, ON, Canada, 1999; pp. 2107-2117.

7. Khan, F.I.; Haddara, M.M. Risk-Based maintenance (RBM): A quantitative approach for maintenance/inspection scheduling and planning. J. Loss Prev. Process. Ind. 2003, 16, 561-573. [CrossRef]

8. Teo, E.A.-L.; Harikrishna, N. A quantitative model for efficient maintenance of plastered and painted façades. Constr. Manag. Econ. 2006, 24, 1283-1293. [CrossRef]

9. Ruiz, F.; Aguado, A.; Serrat, C.; Casas, J.R. Optimal metric for condition rating of existing buildings: Is five the right number? Struct. Infrastruct. Eng. 2019, 15, 740-753. [CrossRef]

10. Goyet, J.; Straub, D.; Faber, M.H. Risk-Based inspection planning of offshore installations. Struct. Eng. Int. 2002, 12, 200-208. [CrossRef]

11. Pereira, C.; Silva, A.; de Brito, J.; Silvestre, J.D. Urgency of repair of building elements: Prediction and influencing factors in façade renders. Constr. Build. Mater. 2020, 249, 118743. [CrossRef]

12. Pereira, C.; de Brito, J.; Silvestre, J.D. Harmonising the classification of the causes of defects in a global building inspection system: Proposed methodology and analysis of fieldwork data. Sustainability 2020, 12, 5564. [CrossRef]

13. Pereira, C.; de Brito, J.; Silvestre, J.D. Harmonising the classification of diagnosis methods within a global building inspection system: Proposed methodology and analysis of fieldwork data. Eng. Fail. Anal. 2020, 115, 104627. [CrossRef]

14. Pereira, C.; de Brito, J.; Silvestre, J.D. Harmonised classification of repair techniques in a global inspection system: Proposed methodology and analysis of fieldwork data. J. Perform. Constr. Facil. 2020, in press.

15. Flores-Colen, I.; de Brito, J.; de Freitas, V.P. Expedient in situ test techniques for predictive maintenance of rendered façades. J. Build. Apprais. 2006, 2, 142-156. [CrossRef]

16. Elcometer Inspection Equipment: Elcometer 143-Crack Width Ruler. Available online: https://www. elcometer.com/images/stories/PDFs/Datasheets/English/143.pdf (accessed on 18 November 2019).

17. Johnson, R.W. The significance of cracks in low-rise buildings. Struct. Surv. 2002, 20, 155-161. [CrossRef]

18. Akbari, R. Crack survey in unreinforced concrete or masonry abutments in short- and medium-span bridges. J. Perform. Constr. Facil. 2013, 27, 203-208. [CrossRef]

19. Hård, A.; Sivik, L.; Tonnquist, G. NCS, natural color system-From concept to research and applications. Part I Color Res. Appl. 1996, 21, 180-205. [CrossRef]

20. ASTM International. ASTM D1535-14(2018) Standard Practice for Specifying Color by the Munsell System; ASTM International: West Conshohocken, PA, USA, 2018.

21. Tyler, J.E.; Hardy, A.C. An analysis of the original Munsell color system. J. Opt. Soc. Am. 1940, 30, 587-590. [CrossRef]

22. Garcez, N.; Lopes, N.; de Brito, J.; Silvestre, J. System of inspection, diagnosis and repair of external claddings of pitched roofs. Constr. Build. Mater. 2012, 35, 1034-1044. [CrossRef]

23. Garcez, N.; Lopes, N.; de Brito, J.; Sá, G. Pathology, diagnosis and repair of pitched roofs with ceramic tiles: Statistical characterisation and lessons learned from inspections. Constr. Build. Mater. 2012, 36, 807-819. [CrossRef]

24. Walter, A.; de Brito, J.; Lopes, J.G. Current flat roof bituminous membranes waterproofing systems-Inspection, diagnosis and pathology classification. Constr. Build. Mater. 2005, 19, 233-242. [CrossRef] 
25. Conceição, J.; Poça, B.; de Brito, J.; Flores-Colen, I.; Castelo, A. Inspection, diagnosis, and rehabilitation system for flat roofs. J. Perform. Constr. Facil. 2017, 31, 04017100. [CrossRef]

26. Conceição, J.; Poça, B.; de Brito, J.; Flores-Colen, I.; Castelo, A. Data analysis of inspection, diagnosis, and rehabilitation of flat roofs. J. Perform. Constr. Facil. 2019, 33, 04018100. [CrossRef]

27. Santos, A.; Vicente, M.; de Brito, J.; Flores-Colen, I.; Castelo, A. Analysis of the inspection, diagnosis, and repair of external door and window frames. J. Perform. Constr. Facil. 2017, 31, 04017098. [CrossRef]

28. Santos, A.; Vicente, M.; de Brito, J.; Flores-Colen, I.; Castelo, A. Inspection, diagnosis, and rehabilitation system of door and window frames. J. Perform. Constr. Facil. 2017, 31, 04016118. [CrossRef]

29. Sá, G.; Sá, J.; de Brito, J.; Amaro, B. Statistical survey on inspection, diagnosis and repair of wall renderings. J. Civ. Eng. Manag. 2015, 21, 623-636. [CrossRef]

30. Sá, G.; Sá, J.; de Brito, J.; Amaro, B. Inspection and diagnosis system for rendered walls. Int. J. Civ. Eng. 2014, 12, 279-290.

31. Amaro, B.; Saraiva, D.; de Brito, J.; Flores-Colen, I. Statistical survey of the pathology, diagnosis and rehabilitation of ETICS in walls. J. Civ. Eng. Manag. 2014, 20, 511-526. [CrossRef]

32. Amaro, B.; Saraiva, D.; de Brito, J.; Flores-Colen, I. Inspection and diagnosis system of ETICS on walls. Constr. Build. Mater. 2013, 47, 1257-1267. [CrossRef]

33. Pires, R.; de Brito, J.; Amaro, B. Inspection, diagnosis, and rehabilitation system of painted rendered façades. J. Perform. Constr. Facil. 2015, 29, 04014062. [CrossRef]

34. Pires, R.; de Brito, J.; Amaro, B. Statistical survey of the inspection, diagnosis and repair of painted rendered façades. Struct. Infrastruct. Eng. 2015, 11, 605-618. [CrossRef]

35. da Silva, C.; Coelho, F.; de Brito, J.; Silvestre, J.; Pereira, C. Inspection, diagnosis, and repair system for architectural concrete surfaces. J. Perform. Constr. Facil. 2017, 31, 04017035. [CrossRef]

36. da Silva, C.; Coelho, F.; de Brito, J.; Silvestre, J.; Pereira, C. Statistical survey on inspection, diagnosis and repair of architectural concrete surfaces. J. Perform. Constr. Facil. 2017, 31, 04017097. [CrossRef]

37. Silvestre, J.D.; de Brito, J. Ceramic tiling inspection system. Constr. Build. Mater. 2009, 23, 653-668. [CrossRef]

38. Silvestre, J.D.; de Brito, J. Ceramic tiling in building façades: Inspection and pathological characterization using an expert system. Constr. Build. Mater. 2011, 25, 1560-1571. [CrossRef]

39. Silvestre, J.D.; de Brito, J. Inspection and repair of ceramic tiling within a building management system. J. Mater. Civ. Eng. 2010, 22, 39-48. [CrossRef]

40. Neto, N.; de Brito, J. Validation of an inspection and diagnosis system for anomalies in natural stone cladding (NSC). Constr. Build. Mater. 2012, 30, 224-236. [CrossRef]

41. Neto, N.; de Brito, J. Inspection and defect diagnosis system for natural stone cladding. J. Mater. Civ. Eng. 2011, 23, 1433-1443. [CrossRef]

42. Delgado, A.; Pereira, C.; de Brito, J.; Silvestre, J.D. Defect characterization, diagnosis and repair of wood flooring based on a field survey. Mater. Constr. 2018, 68, 1-13. [CrossRef]

43. Delgado, A.; de Brito, J.; Silvestre, J.D. Inspection and diagnosis system for wood flooring. J. Perform. Constr. Facil. 2013, 27, 564-574. [CrossRef]

44. Garcia, J.; de Brito, J. Inspection and diagnosis of epoxy resin industrial floor coatings. J. Mater. Civ. Eng. 2008, 20, 128-136. [CrossRef]

45. Carvalho, C.; de Brito, J.; Flores-Colen, I.; Pereira, C. Inspection, diagnosis, and rehabilitation system for vinyl and linoleum floorings in health infrastructures. J. Perform. Constr. Facil. 2018, 32, 04018078. [CrossRef]

46. Carvalho, C.; de Brito, J.; Flores-Colen, I.; Pereira, C. Pathology and rehabilitation of vinyl and linoleum floorings in health infrastructures: Statistical survey. Buildings 2019, 9, 116. [CrossRef]

47. European Committee for Standardization. EN ISO 4628-4:2016 Paints and Varnishes-Evaluation of Degradation of Coatings-Designation of Quantity and Size of Defects, and of Intensity of Uniform Changes in Appearance-Part. 4: Assessment of Degree of Cracking (ISO 4628-4:2016); European Committee for Standardization: Brussels, Belgium, 2016.

48. European Committee for Standardization. EN ISO 4628-2:2016 Paints and varnishes-Evaluation of Degradation of Coatings-Designation of Quantity and Size of Defects, and of Intensity of Uniform Changes in Appearance-Part. 2: Assessment of Degree of Blistering (ISO 4628-2:2016); European Committee for Standardization: Brussels, Belgium, 2016.

49. van Winden, C.; Dekker, R. Rationalisation of building maintenance by Markov decision models: A pilot case study. J. Oper. Res. Soc. 1998, 49, 928-935. [CrossRef] 
50. Flourentzou, F.; Brandt, E.; Wetzel, C. MEDIC-A method for predicting residual service life and refurbishment investment budgets. Energy Build. 2000, 31, 167-170. [CrossRef]

51. Brandt, E.; Wittchen, K.B.; Faist, A.; Genre, J.L. EPIQR-A new surveying tool for maintenance and refurbishment. In Durability of Building Materials and Componentes 8; Lacasse, M.A., Vanier, D.J., Eds.; National Research Council Canada: Ottawa, ON, Canada, 1999; pp. 1576-1584.

52. Flourentzos, F.; Droutsa, K.; Wittchen, K.B. EPIQR software. Energy Build. 2000, 31, 129-136. [CrossRef]

53. Allehaux, D.; Tessier, P. Evaluation of the functional obsolescence of building services in European office buildings. Energy Build. 2002, 34, 127-133. [CrossRef]

54. National Aeronautics and Space Administration. Reliability-Centered Maintenance Guide for Facilities and Collateral Equipment; National Aeronautics and Space Administration: Washington, DC, USA, 2008.

55. Rodrigues, M.F.S.; Teixeira, J.M.C.; Cardoso, J.C.P. Buildings envelope anomalies: A visual survey methodology. Constr. Build. Mater. 2011, 25, 2741-2750. [CrossRef]

56. Elhakeem, A.; Hegazy, T. Building asset management with deficiency tracking and integrated life cycle optimisation. Struct. Infrastruct. Eng. 2012, 8, 729-738. [CrossRef]

57. Morgado, J.; Flores-Colen, I.; de Brito, J.; Silva, A. Maintenance planning of pitched roofs in current buildings. J. Constr. Eng. Manag. 2017, 143, 05017010. [CrossRef]

58. Morgado, J.; Flores-Colen, I.; de Brito, J.; Silva, A. Maintenance programs for flat roofs in existing buildings. Prop. Manag. 2017, 35, 339-362.

59. Uzarski, D.R.; Grussing, M.N.; Mehnert, B.B. ERDC/CERL SR-18-7 Knowledge-Based Condition Assessment Reference Manual for Building Component-Sections. For. Use with BUILDER ${ }^{\mathrm{TM}}$ and BuilderRED ${ }^{\mathrm{TM}}$ (v. 3 Series); Construction Engineering Research Laboratory, US Army Engineer Research and Development Center: Champaign, IL, USA, 2018.

60. Lee, J.-S. Value engineering for defect prevention on building façade. J. Constr. Eng. Manag. 2018, 144, 04018069. [CrossRef]

61. Bortolini, R.; Forcada, N. Building inspection system for evaluating the technical performance of existing buildings. J. Perform. Constr. Facil. 2018, 32, 04018073. [CrossRef]

62. Silva, A.; de Brito, J.; Gaspar, P.L. Green Energy and Technology. In Methodologies for Service Life Prediction of Buildings. With a Focus on Façade Claddings; Springer: Cham, Switzerland, 2016; ISBN 978-3-319-33288-8.

63. Ruiz, F.; Aguado, A.; Serrat, C.; Casas, J.R. Condition assessment of building façades based on hazard to people. Struct. Infrastruct. Eng. 2019, 15, 1346-1365. [CrossRef]

64. Fernandes, D.; de Brito, J.; Silva, A. Methodology for service life prediction of window frames. Can. J. Civ. Eng. 2019, 46, 1010-1020. [CrossRef]

65. van Hees, R.P.J.; Binda, L.; Papayianni, I.; Toumbakari, E. Characterisation and damage analysis of old mortars. Mater. Struct. 2004, 37, 644-648. [CrossRef]

66. Blocken, B.; Derome, D.; Carmeliet, J. Rainwater runoff from building facades: A review. Build. Environ. 2013, 60, 339-361. [CrossRef]

67. Júnior, C.M.M.; Carasek, H. Relationship between the deterioration of multi story buildings facades and the driving rain. Rev. Constr. 2014, 13, 64-73.

68. National Precast Concrete Association. Precast Concrete Architectural Repair Guide; National Precast Concrete Association: Carmel, IN, USA, 2013.

69. Gaspar, P.L. End of the service life of ceramic cladding: Lessons from the Girasol Building in Madrid. J. Perform. Constr. Facil. 2017, 31, 04016088. [CrossRef]

(C) 2020 by the authors. Licensee MDPI, Basel, Switzerland. This article is an open access article distributed under the terms and conditions of the Creative Commons Attribution (CC BY) license (http://creativecommons.org/licenses/by/4.0/). 